\title{
UTILIZAÇÃO DA METODOLOGIA DE CUSTEIO ABC NA FORMAÇÃO DO PREÇO DE VENDA DE SERVIÇOS NA EMPRESA “ALFA” EM TANGARÁ DA SERRA - MT
}

\author{
Edenize de Almeida Gomes ${ }^{1}$ \\ Marcelo Evandro Alves ${ }^{2}$
}

\section{RESUMO}

Nos dias atuais, o controle dos custos nas empresas tem sido um fator relevante para a tomada das decisões dos gestores. Diante disso o presente artigo procurou evidenciar o custo por atividade na empresa "Alfa" utilizando o sistema de custeio ABC, a empresa atua no ramo de prestação de serviços em eletrodomésticos e climatização de ambientes, e não utiliza nenhum sistema de custeio. Dessa forma a análise identificou os principais sistemas de custeio e de que maneiras pode-se aplicar essas metodologias em empresas prestadoras de serviço, que é o caso da entidade estudada. Trata-se de uma pesquisa descritiva com abordagem quantitativa, onde através de pesquisas bibliográficas foram conceituados os termos custos e despesas. No caso da empresa em análise sugere-se que seja utilizado o sistema de custeio $\mathrm{ABC}$, já que através dele os custos são consumidos pelas atividades realizadas na empresa, além disso, o estudo contribuiu, através das observações realizadas, de que maneiras as empresas podem identificar os custos, detectando as falhas, para que posteriormente essas falhas possam ser corrigidas. Foram identificados os valores dos custos diretos, indiretos e principais despesas da empresa e posteriormente com o auxilio do mark-up, simulado o preço de venda. Com base nos resultados obtidos foi feito uma comparação do preço dos serviços praticados, com o preço simulado na análise, constatando-se que com o preço simulado, a empresa não obteve rendimento favorável.

Palavras-chave: Controle de custos, Preço de Venda, Departamentos.

\section{INTRODUÇÃO}

A revolução da prestação de serviços na economia está em constante crescimento, desempenhando um importante papel tanto para quem consome produtos ou serviços, quanto para aquele que vende ou presta serviços. Uma das mais importantes decisões de qualquer empresa é estipular corretamente os preços de venda de seus produtos ou serviços, de forma a manter o equilíbrio entre o custo e o lucro (LOBRIGETTI, 2010).

Com a competitividade cada vez mais acirrada e a necessidade das empresas na busca de resultados positivos, há a necessidade do empresário conhecer os seus custos de forma clara e objetiva. Muitos não têm esta visão da importância dos custos para suas empresas e pagam caro até com o fechamento destas pela falta de controle e planejamento de seus custos (BEULKE; BERTÓ, 2001).

\footnotetext{
${ }^{1}$ Acadêmica do curso de Ciências Contábeis da UNEMAT - Campus de Tangará da Serra, e-mail: denise_eag@hotmail.com

${ }^{2}$ Professor do Departamento de Ciências Contábeis da UNEMAT - Campus de Tangará da Serra, e-mail: marcelo.evandro@unemat.br 
Esta pesquisa foi desenvolvida para auxiliar os empresários na tomada de decisões que possam contribuir para o crescimento da empresa, haja visto que a maioria das empresas não utilizam os sistemas de custeio que existem e que o preço de venda dos produtos e serviços quase sempre não superam os custos e despesas incorridos para obtenção dos mesmos.

Dessa forma, a pesquisa contribuiu, através das análises, qual a melhor maneira de praticar o preço de venda dos serviços e assim identificou também qual o custo que cada atividade gera para empresa. O problema abordado na pesquisa foi "qual o custo dos departamentos da empresa Alfa utilizando o sistema de custeio ABC?"

O presente artigo teve como objetivo evidenciar os custos e despesas por atividade incorridos em uma empresa prestadora de serviços, que tem como principal atividade econômica prestação de serviços em eletrodomésticos e climatização de ambientes, no município de Tangará da Serra - MT e, com isso foi realizado uma simulação do preço de venda de serviços com o auxílio do mark-up, onde as hipóteses foram as seguintes:

Hipótese 1 - A metodologia de custeio ABC é aplicável em empresas prestadoras de serviço.

Hipótese 2 - $\mathrm{O}$ sistema de custeio $\mathrm{ABC}$, assim como nas indústrias traz benefícios para as empresas prestadoras de serviço.

Os objetivos específicos do presente artigo foram conceituar os termos custos, despesas e métodos de custeio, foi feito o levantamento dos custos e despesas por atividade e por fim comparado os custos apurados com as receitas incorridas na empresa Alfa.

\section{REFERENCIAL TEÓRICO}

Segundo Ribeiro, Torres e Rocha (2006) "para ter credibilidade, um trabalho acadêmico deve fundamentar-se em teorias conhecidas, ou seja "revisar" a literatura anteriormente publicada, apoiando-se assim em uma base sólida de conhecimentos e práticas conhecidas".

\subsection{Contabilidade de custos}

A Contabilidade de Custos conforme descreve Martins (2003), nasceu da Contabilidade Financeira, quando da necessidade de avaliar estoques nas indústrias, tarefa 
Utilização da metodologia de custeio ABC na formação do preço de venda de serviços na empresa "Alfa"

em Tangará da Serra - MT

Edenize de Almeida Gomes

Marcelo Evandro Alves

essa que era fácil na típica empresa na era do mercantilismo. Sua finalidade era atender completamente duas importantes tarefas: controle e decisão.

A Contabilidade de custos é um instrumento de controle dinâmico, pois acompanha os fatos internos na empresa, e funciona como instrumento de tomada de decisões. Ela tem a função de gerar informações precisas e rápidas para a administração, para a tomada de decisões (MEDEIROS, 1994).

O conhecimento dos custos na organização se faz necessário para atingir a margem de lucro desejada, mas para que isso aconteça, a empresa deve se estruturar em uma metodologia de custeio que são alimentadas por informações coletadas dentro de todos os setores da empresa, e essas informações devem ser confiáveis e reais para assim poder gerar resultados para que o gestor possa alcançar os objetivos traçados (CREPALDI, 2004).

A contabilidade de custos pode ser usada como instrumento de gestão sendo imprescindível para o bom andamento da saúde financeira de uma empresa, bem como apresenta um sistema de informação onde disponibiliza dados necessários para que se possa medir o desempenho da organização, tanto curto no como no longo prazo, pois há uma ligação direta com as funções de planejamento, orçamento e controle (MEGLIORINI, 2007).

\subsection{Conceito de Custo}

Na concepção de Beulke e Bertó (2001), “custo é a expressão monetária que deve ter uma menor quantidade final, boa, vendável de produtos e serviços para repor fisicamente, ao termino de cada ciclo operacional, uma maior quantidade inicial de insumos e consumo do ciclo".

A palavra custo também significa o preço original de aquisição de qualquer bem ou serviço, inclusive leigamente; daí se falar em "custo de uma obra" "custo de um automóvel adquirido", "custo de uma consulta", etc. (MARTINS, 2003). O custo de um produto é a soma de todos os custos que podem ser a eles identificados, e devem incluir tanto o custo direto como o custo indireto (SANTOS, 2005). O custo é o gasto relativo à bem ou serviço utilizado na produção de outros bens ou serviço (MARTINS, 2003).

Para Bruni e Famá (2002), custos representam os gastos relativos a bens ou serviços utilizados na produção de outros bens ou serviços. De acordo com Megliorini (2007) "os custos nas empresas prestadoras de serviço, correspondem aos gastos relativos à execução dos 
Utilização da metodologia de custeio ABC na formação do preço de venda de serviços na empresa "Alfa"

em Tangará da Serra - MT

Edenize de Almeida Gomes

Marcelo Evandro Alves

serviços. As despesas correspondem aos gastos relacionados à administração da empresa e a geração de receitas incorridas durante o exercício".

Na concepção de Bruni (2002), “ os custos constituem a expressão monetária dos valores ocorridos para venda de um determinado produto ou serviço, os custos ocorrem a sua atividade produtiva, sendo assim tem que arcar com eles para realização dos seus negócios".

Sabiamente, não existe Custo ou Despesa eternamente fixo: são, isso sim, fixos dentro de certos limites de oscilação da atividade a que se referem, sendo que, após tais limites, aumentam, mas não de forma exatamente proporcional, tendendo a subir em "degraus", assim, o custo com a supervisão de uma fábrica pode manter-se constantemente até que ela atinja sua capacidade (MARTINS, 2003).

O custo pode ser identificado no produto, são os gastos direcionados a produção de bens, portanto, inerentes a atividade de produzir, incluindo a produção em si e a administração da produção.A contabilidade de custos requer assim, a existência de métodos de custeio para que, ao final do processo, seja possível obter-se o valor a ser atribuído ao objeto produzido (BENARDI, 1998).

Martins (2003), admite que custo é um gasto; porém relata que é o momento da utilização dos fatores de produção que o difere dos demais gastos. Baseado nisso, custos seriam materiais diretos ou indiretos (consumidos na produção), mão de obra direta e indireta de fabricação ou execução de serviços, e os demais gastos diretos e indiretos de fabricação.

Na visão de Garrison (2001), os custos são apropriados aos objetos para uma série de finalidades, incluindo a formação de preço, análise de rentabilidade e controle de gastos. $\mathrm{O}$ objeto de custeio é qualquer coisa, como por exemplo, produtos, linhas de produtos, clientes, tarefas e subunidades da organização, para a qual se deseja a informação de custo.

Conforme Martins (2003), além de serem agrupados em diretos e indiretos, os custos podem ser agrupados em fixos e variaveis.

De acordo com Leone (1991), as empresas classificam os custos entre custos fixos e custos variáveis, baseados em seu comportamento em resposta as mudanças no volume de produção. Para Bruni (2002) os custos fixos são definidos como os que se mantem inalterados, dentro de certos limites, independentemente das variações das atividades ou vendas, muitas vezes sofrem algumas alterações devidas apenas a inflação ou acréscimo de preços.

\subsection{Métodos de custeio}


Segundo Bornia (2002), o método de custeio é a forma pela qual os custos são apropriados, ou seja, alocados aos seus produtos finais, que podem ser tanto produtos como serviços. A alocação dos custos aos produtos é feita por meio de métodos de custeio e estes são: custeio por absorção, custeio variável, custeio baseado em atividades e custo padrão.

“Custeio por absorção é o método derivado da aplicação dos principios de contabilidade geralmente aceitos, nascido da situação histórica mencionada. Consiste na apropriação de todos os custos de produção aos bens elaborados, todos os esforços relativos aos bens de produção; todos os gastos relativos aos esforços de produção são distribuidos para todos os produtos ou serviços feitos".(MARTINS,2003).

Para Megliorini (2007), “o custeio por absorção é um método que consiste em apropriar todos os custos seja ele direto, indireto, fixos ou variaveis", " a distinção do custeio por absorção é entre os custos e despesas, pois neste método as despesas são contabilizadas diretamente no resultado do periodo, e somente os custos relativos aos produtos vendidos são os que terão o mesmo tratamento".

"A principal diferença do uso do custeio por absorção é entre custos e despesas. A separação é importante porque as despesas são lançadas diretamente contra o resultado do periodo, enquanto que apenas os custos identificados aos produtos terão o mesmo tratamento"(CREPALDI, 2004).

Ainda na concepção de Crepaldi (2004), "quanto aos fins gerenciais este método apresenta desvantagem no fornecimento de informações, pois os gastos que não fazem parte da produção são considerados como despesas do periodo.

Kaplan e Cooper (1998), consideram que as empresas precisam de sistemas de custeio para realizar três funções principais:

- Avaliar os estoques e medir o custo dos bens vendidos para geração de relatórios financeiros;

- $\quad$ Estimar as despesas operacionais, produtos, serviços e clientes;

- Oferecer feedback econômico sobre a eficiência do processo a gerentes e operadores.

\subsection{Custeio baseado em atividades (ABC)}

Conhecido como custeio ABC, essa ferramenta de gestão de custos busca a redução, de forma bastante sensível, das distorções provocadas pelos métodos de rateio arbitrário dos custos indiretos, embora esse método possa também ser aplicado aos custos indiretos, 
Utilização da metodologia de custeio ABC na formação do preço de venda de serviços na empresa "Alfa" em Tangará da Serra - MT

Edenize de Almeida Gomes

Marcelo Evandro Alves

principalmente à mão de obra direta, apesar de não trazer diferenças significativas se comparado aos métodos tradicionais de custeio (MARTINS, 2003).

Para Dutra (2003), o método de custeio baseado em atividades originou-se da tentativa de melhorar a qualidade da informação contábil para a tomada de decisões, principalmente com relação a produtividade da força de trabalho.

O sistema de custeio “Activity Basead Costing” (ABC) permite a apuração dos custos dos produtos, serviços ou outros objetos de custeio partindo da seguinte filosofia: os recursos de uma empresa são consumidos pelas atividades executadas. Assim, aos custos indiretos são apropriados, inicialmente, as atividades e, em uma etapa seguinte, aos produtos, serviços e outos objetos de custeio (MEGLIORINI, 2007).

O custo de uma atividade inclui todos os fatores de produção empregados para desempenhá-la. Os fatores de produção consiste em pessoas, máquinas, viagens, suprimentos, sistemas de informação e outros recursos que são normalmente denominados elementos de custo dentro de um plano de contas. Cada fator de produção significatível e identificável é incluido no custo de uma atividade (BRIMSON, 1996).

Para Cogan (2000), um dos beneficios obtidos com o "ABC" é o de permitir uma melhoria nas decisões gerenciais pois, deixa-se de ter produtos "subcusteados" ou "supercusteados", permitindo-se a transparência exigida na tomada de decisão empresarial, que busca em última análise otimizar a rentabilidade do negócio.

As empresas de serviço são candidatas ideais ao custeio com base em atividade, uma vez que quase a totalidade de seus custos é classificada como indireto e aparentemente fixos; nas empresas de serviço, o volume de materiais diretos é mínimo, e a maior parte de sua mão de obra oferece um suporte indireto a produtos e clientes (KAPLAN;COOPER ,1998).

\subsection{Mark-up}

De acordo com Megliorini ( 2007 ), o mark-up consiste em uma margem em forma de indice ou percentual, que é adicionada ao custos dos produtos e esse custo pode apresentar variações dependendo do método de custeio utilizado.

Para se calcular o preço de venda pode-se utilizar o mark-up, essa palavra vem do inglês que significa marca acima, é um indice que aplicado sobre os gastos de um bem ou serviço, possibilita a obtenção do preço de venda (BRUNI, 2002). 
Utilização da metodologia de custeio ABC na formação do preço de venda de serviços na empresa "Alfa"

em Tangará da Serra - MT

Edenize de Almeida Gomes

Marcelo Evandro Alves

O mark-up pode ser calculado de forma multiplicador, que consiste em representar um percentual que é multiplicado pelos custos variáveis. Outra forma de mark-up é o divisor, que representa os gastos integrais em relação ao preço de venda (MEGLIORINI,2007).

A idéia de que uma das finalidades da contabilidade de custos é a obtenção do preço de venda se torna generalizada, pois para que se tenha um bom desempenho na administração do preço de venda, é necessário conhecer o custo do produto (MARTINS,2003).

Fórmula do mark-up divisor:

$\mathrm{MKD}=\underline{100 \%-(\% \mathrm{DV}+\% \mathrm{DF}+\mathrm{MLD})}$

100

Onde:

MKD: MARK-UP DIVISOR

DV: DESPESAS VARIÁVEIS

DF: DESPESA FIXAS

MLD: MARGEM DE LUCRO DESEJADA

Fórmula do mark-up multiplicador:

$\mathrm{MKM}=1 / \mathrm{MKM}$

Onde:

MKM: MARK-UP MULTIPLICADOR

\subsection{Alocação dos custos em empresas prestadoras de serviço}

Uma empresa prestadora de serviços opera com venda de trabalho, podendo ou não utilizar materiais, peças, produtos, componentes entre outros para a execução de serviço. E pequenas ações são necessárias para que isto aconteça com certa rentabilidade (OLIVEIRA,2010).

De acordo com Padoveze (2003), "um serviço é qualquer ato ou desempenho essencialmente intangível que uma parte pode oferecer a outra e que não tem a propriedade de algo".

Muitas literaturas sobre custos referem-se apenas a empresas indutriais, certamente os autores acreditam que essas empresas possuam atividades e estruturas mais complexas do que as organizações que atuam no ramo comecial ou prestação de serviços, porém muitos conceitos aplicados as empresas indutriais podem ser utilizados também em empresas comerciais e de prestação de serviços, pois estas originam gastos para a realização de suas atividades operacionais (CREPALDI, 2004).

A grande parte das empresas prestadoras de serviços tem diferenças em relação aos custos totais, alguns gastos só acontecem quando o cliente solicita o serviço. Ocorrendo assim 
Utilização da metodologia de custeio ABC na formação do preço de venda de serviços na empresa "Alfa"

em Tangará da Serra - MT

Edenize de Almeida Gomes

Marcelo Evandro Alves

uma separação dos valores gastos em custos dos serviços; despesas fixas e despesas variáveis ( LOBRIGETTI,2010).

Riccio (1998) afirma que na maioria dos países, as empresas de serviços representam a maior parcela do PIB. Ele defende ainda que a área de serviços é a que mais cresce e que é esta a tendência para os próximos anos. Além disso, esse setor pode ser considerado como uma forma de viabilizar as atividades dos outros setores, por este motivo, até mesmo dentro da indústria, o setor de serviços torna-se peça-chave, ampliando sua atuação dentro da economia dos outros setores.

Ainda de acordo com Riccio (1998), as empresas de serviços diferem-se das indústrias em vários aspectos. As primeiras não possuem estoques por exemplo: seus produtos são compostos e na maioria das vezes são intangíveis, sendo que os tangíveis podem agregar algo aquele serviço. Além disso, nas empresas de serviços a relação com o cliente é diferente, é ele quem determina o sentido e a direção pelos quais os processos devem se orientar.

Mauad;Pamplona (2003) relata que "os serviços estão no centro da atividade econômica em todos os países". Fitzsimmons(2000) afirma que nos anos 90 a economia deixou de ser predominantemente manufaturada, passando para o setor de serviços.

Mauad;Pamplona (2003) descreve que gerir serviços é algo bem diferente de gerir uma produção de bens. Porém é mais importante conhecer o que caracteriza serviços do que entender essa diferença, num primeiro momento. As caracteristicas dos serviços são: intangibilidade, necessidade da presença do cliente e produção e consumo simultâneo dos serviços.

Para Padoveze (2003), a apuração do custo unitário dos serviços segue a mesma forma de custeamento dos produtos. A empresa prestadora de serviços deve estudar sua estrutura e tentar se encaixar num dos métodos de custeamento que empresas industriais utilizam.

A grande parte das empresas prestadoras de serviço tem diferenças em relação aos custos totais, alguns gastos só acontecem quando o cliente solicita o serviço.Ocorrendo assim uma separação dos valores gastos em custos do serviço ( LOBRIGETTI, 2010).

\section{METODOLOGIA}

Segundo Ribeiro, Torres e Rocha (2006) "Método é o caminho a ser seguido a fim de que as metas sejam atingidas. Portanto, a seleção do instrumental metodológico está diretamente relacionada com o problema a ser estudado". 
Utilização da metodologia de custeio ABC na formação do preço de venda de serviços na empresa "Alfa"

em Tangará da Serra - MT

Edenize de Almeida Gomes

Marcelo Evandro Alves

Esta pesquisa teve como objetivo fazer uma análise de custo por departamento utilizando o custeio ABC na formação do preço de venda de serviços da empresa "Alfa" em Tangará da Serra - MT.

O estudo foi realizado em uma empresa prestadora de serviço que tem como atividade econômica principal prestação de serviços em eletrodomésticos e climatização de ambientes. De acordo com Vergara (2000) a pesquisa pode ser classificada seguindo dois critérios, quanto aos fins e quanto aos meios.

Em relação aos fins a pesquisa foi realizada de forma descritiva, devido ao fato de que na pesquisa descritiva é utilizado o método de técnicas padronizadas de coleta de dados. Os dados e informações foram extraídos de documentos da empresa estudada, fornecidos para melhor desempenho da análise.

Quanto aos meios a pesquisa foi classificada como bibliográfica, pois a mesma foi desenvolvida através de publicações em livros, revistas, jornais e internet. Utilizou-se também a pesquisa documental, pois foram utilizados dados fornecidos pela empresa estudada, tais como controle financeiro, relatórios dos custos, relatório de despesas, faturamento da empresa, onde o período estudado foi de janeiro a dezembro de 2011.

Quanto aos procedimentos a pesquisa é classificada como estudo de caso, onde a abordagem do problema será quantitativa, e o método de custeio escolhido foi o sistema de custeio $\mathrm{ABC}$, que é um tipo de custeio que proporciona o levantamento e análise dos dados por atividades.

\section{DISCUSSÃO DE RESULTADOS}

\subsection{Caracterização da Empresa}

A empresa Alfa opera no ramo de prestação de serviços em eletrodomésticos e climatização de ambientes e é optante pelo Simples Nacional, localizando-se no município de Tangará da Serra - MT. Possui em seu quadro de pessoal 17 funcionários, sendo que são 4 funcionários no setor de atendimento, 7 funcionários no setor da oficina e 6 funcionários no setor de climatização de ambientes. Possui dois sócios que dão suporte ao setor de atendimento, atuando nos setores administrativos e responsáveis pelos serviços financeiros, cobranças, recebimentos e pagamentos.

O ramo de prestação de serviços está em constante crescimento, com isso a competição fica cada vez mais acirrada entre o preço de venda que os proprietários de 
Utilização da metodologia de custeio ABC na formação do preço de venda de serviços na empresa "Alfa" em Tangará da Serra - MT

Edenize de Almeida Gomes

Marcelo Evandro Alves

empresas pretendem lançar no mercado.

Com base nos custos foi realizada uma análise na empresa Alfa e posteriormente simulado o preço de venda de três tipos de serviço, aplicando a metodologia de custeio ABC.

\subsection{Tabelas de Separação dos Custos da empresa Alfa}

Tabela 1 - Relação dos Custos Diretos, Empresa Alfa,jan - dez/2011 em R\$.

\begin{tabular}{c|c|c|c|c|c|c|c|c|c|c|c|c|c}
\hline C. Diretos & Jan & Fev & Mar & Abr & Mai & Jun & Jul & Ago & Set & Out & Nov & Dez & Toral \\
\hline Sálarios & $11.784,79$ & $25.980,00$ & $9.857,00$ & $15.955,00$ & $7.505,00$ & $8.366,00$ & $11.162,00$ & $8.359,25$ & $14.301,00$ & $11.486,38$ & $9.460,00$ & $13.198,00$ & $147.414,42$ \\
\hline Encargos & 942,78 & $2.078,40$ & 788,56 & $1.276,40$ & 600,40 & 669,28 & 892,96 & 668,74 & $1.144,08$ & 918,91 & 756,80 & $1.055,84$ & $11.793,15$ \\
\hline T0TAL & $12.727,57$ & $28.058,40$ & $10.645,56$ & $17.231,40$ & $8.105,40$ & $9.035,28$ & $12.054,96$ & $9.027,99$ & $15.445,08$ & $12,405,29$ & $10.216,80$ & $14.253,84$ & $159,207,57$ \\
\hline
\end{tabular}

Fonte: Dados da pesquisa

Na tabela 1 estão relacionados os custos diretos da empresa Alfa incorridos nos meses de janeiro a dezembro de 2011. No custo com a mão de obra direta estão apropriados os salários dos departamentos que a empresa possui, que são salários do setor de climatização, eletrodomésticos e atendimento. Quanto aos encargos sociais e trabalhistas, os valores relacionados são referentes apenas ao FGTS dos funcionários, já que os gestores da empresa Alfa não dispunham de dados suficientes para fornecer para realização da análise.

Os valores dos encargos como férias, décimo terceiro, INSS não foram encontrados nos relatórios da entidade estudada, por este motivo apenas o FGTS será considerado para desenvolvimento da pesquisa.

Diante disso, podemos considerar que a folha de pagamento da empresa Alfa consome grande parte dos custos em determinados meses, onde os maiores custos com a mão de obra direta foram nos meses de fevereiro que chegou ao valor de $\mathrm{R} \$ 25.980,00$ reais e no mês de setembro que chegou ao valor de $\mathrm{R} \$ 14.301,00$.

Vale ressaltar que estes valores gastos com mão de obra direta foram retirados dos relatórios mensais da empresa Alfa. Existe uma oscilação muito grande de valores de um mês para o outro pelo simples fato de que a entidade não controla os reais valores que são pagos aos funcionários, não são feitos os lançamentos de forma correta no sistema empresarial da entidade, sendo considerado os dados que foram apresentados pela empresa. 
Utilização da metodologia de custeio ABC na formação do preço de venda de serviços na empresa "Alfa"

em Tangará da Serra - MT

Edenize de Almeida Gomes

Marcelo Evandro Alves

Tabela 2 - Relação dos Custos Indiretos no Setor de Oficina da Empresa Alfa - Janeiro a Dezembro de 2011.

\begin{tabular}{|c|c|c|c|c|c|c|c|c|c|c|c|c|c|}
\hline C. Indiretos & Jan & $\mathrm{Fev}$ & Mar & $\mathrm{Abr}$ & Mai & Jun & Jul & $\mathrm{Ag}_{0}$ & Set & Out & Nov & Dez & Toral \\
\hline $\begin{array}{l}\text { Agua/Luz/ } \\
\text { Telefone }\end{array}$ & $1.927,98$ & $1.975,30$ & $1.676,16$ & $1.597,70$ & $1.715,30$ & $2.690,15$ & $1.036,24$ & $3.092,66$ & $2.640,12$ & $3.244,37$ & $2.398,67$ & $2.444,01$ & $26.438,66$ \\
\hline $\begin{array}{l}\text { Materiais } \\
\text { Diversos }\end{array}$ & 529,19 & 532,85 & 391,04 & 228,50 & 457,60 & 359,27 & 752,83 & 576,95 & 296,56 & 197,93 & 179,87 & 553,00 & $5.055,59$ \\
\hline Ferramentas & 88,00 & 28,00 & 172,00 & 116,00 & 25,00 & 115,00 & 34,00 & 18,00 & 187,00 & 22,00 & 243,00 & 178,00 & $1.226,00$ \\
\hline $\begin{array}{c}\text { Materiais de } \\
\text { Limpeza }\end{array}$ & 58,00 & 28,00 & 49,00 & 74,87 & 42,00 & 131,00 & 62,00 & 166,26 & 49,00 & 56,00 & 77,00 & 39,50 & 832,63 \\
\hline TOTAL & $2.603,17$ & $2.564,15$ & $2.288,20$ & $2.017,07$ & $2.239,90$ & $3.295,42$ & $1.885,07$ & $3.853,87$ & $3.172,68$ & $3.520,30$ & $2.898,54$ & $3.214,51$ & $33.552,88$ \\
\hline
\end{tabular}

Fonte: Dados da Pesquisa

A Tabela 2 demonstra os custos indiretos da empresa Alfa incorridos nos meses de janeiro a dezembro de 2011, visto que os maiores custos indiretos são provenientes do consumo de água, energia e telefone. Devemos considerar que o consumo da água, energia e telefone são provenientes de todos os departamentos, todas as atividades desenvolvidas pela empresa, por isso os valores ficaram mais elevados que os demais custos.

Os demais custos indiretos que são materiais diversos, ferramentas, materiais de limpeza são lançados integralmente como despesas nos controles da empresa Alfa.

Tabela 3 -Relação das Atividades Desenvolvidas na Empresa Alfa

\begin{tabular}{l|l}
\hline \multicolumn{1}{c|}{ DEPARTAMENTOS } & ATIVIDADES \\
\hline Atendimento & Atendimentos de clientes; aprovação dos serviços \\
Oficina & Realizar orçamentos; execução dos serviços \\
Climatização & Instalação dos condicionadores de ar; recebimento dos serviços \\
\hline
\end{tabular}

Fonte: Dados da Pesquisa

A Tabela 3 demonstra as atividades desenvolvidas pelos departamentos na empresa Alfa, onde o setor de atendimento é responsável por todas as aprovações de serviços dos produtos e atendimento em geral aos clientes. Os funcionários desse setor são responsáveis por todo atendimento telefônico, dando orientações sobre funcionamento dos produtos, sugestões e reclamações. No momento do atendimento direto, que acontece quando o cliente vai até o estabelecimento levando seus produtos ou solicitando os serviços da empresa Alfa.

O setor de oficina é responsável pela realização e execução dos orçamentos que são 
Utilização da metodologia de custeio ABC na formação do preço de venda de serviços na empresa "Alfa" em Tangará da Serra - MT

Edenize de Almeida Gomes

Marcelo Evandro Alves

aprovados pelo setor de atendimento. E o setor de climatização fica com a responsabilidade de aprovação dos serviços de instalações dos condicionadores de ar e recebimentos dos serviços prestados, tanto para empresas quanto para consumidores.

Tabela 4 - Faturamento da Empresa Alfa - Jan 2011 a Dez 2011

\begin{tabular}{l|c}
\hline MESES & TOTAIS \\
\hline Janeiro & $69.129,66$ \\
\hline Fevereiro & $84.901,92$ \\
\hline Março & $80.268,93$ \\
\hline Abril & $72.788,68$ \\
\hline Maio & $67.515,69$ \\
\hline Junho & $88.600,97$ \\
\hline Julho & $64.421,14$ \\
\hline Agosto & $89.528,07$ \\
\hline Setembro & $78.306,67$ \\
\hline Outubro & $57.701,18$ \\
\hline Novembro & $102.070,85$ \\
\hline Dezembro & $75.953,78$ \\
\hline TOTAL & $931.187,54$ \\
\hline Fonte: Dados da Pesquisa &
\end{tabular}

Fonte: Dados da Pesquisa

Na tabela 4 estão relacionados os valores do faturamento incorrido na empresa Alfa nos meses de janeiro a dezembro de 2011. Nota-se que o mês em que o índice de maior faturamento foi o mês de novembro, onde o valor total do faturamento ficou no valor de $\mathrm{R} \$$ 102.070,85 e o mês onde a empresa Alfa teve o menor índice de faturamento foi no mês de outubro, no valor de R \$ 57.701,18.

Como a empresa Alfa atua no ramo de prestação de serviços em eletrodomésticos, dificilmente tem um mês que podemos dizer que há pouco movimento, durante o ano todos os meses tem um percentual de atendimentos significativo na entidade, ou seja, o fato do faturamento no mês de outubro ter sido baixo com relação aos outros, não significa que este é um mês sem movimento para empresa. 
Utilização da metodologia de custeio ABC na formação do preço de venda de serviços na empresa "Alfa" em Tangará da Serra - MT

Edenize de Almeida Gomes

Marcelo Evandro Alves

Tabela 5 - Relação das Despesas, Empresa Alfa - Janeiro a Dezembro de 2011

\begin{tabular}{|c|c|c|c|c|c|c|c|c|c|c|c|c|}
\hline Despesas & Jan & $\mathrm{Fev}$ & Mar & $\mathrm{Abr}$ & Mai & Jun & Jul & Ago & Set & Out & Nov & Dez \\
\hline $\begin{array}{c}\text { Agua/Luz/ } \\
\text { Telefone/ } \\
\text { Atendimento } \\
\end{array}$ & 243,98 & 342,98 & 432,10 & 552,98 & $1.089,78$ & 216,90 & 768,09 & 765,34 & 222,98 & 523,98 & 765,98 & 342,19 \\
\hline $\begin{array}{l}\text { Honorários } \\
\text { Contábeis }\end{array}$ & $1.069,00$ & $1.069,00$ & $1.069,00$ & $1.069,00$ & $1.069,00$ & $1.069,00$ & $1.069,00$ & $1.069,00$ & $1.069,00$ & $1.069,00$ & $1.069,00$ & $1.069,00$ \\
\hline Combustiveis & 521,98 & 789,09 & 712,87 & 645,66 & 689,00 & 715,00 & 220,99 & 345,76 & 567,99 & 456,98 & 789,76 & 644,28 \\
\hline $\begin{array}{l}\text { Materiais } \\
\text { Limpeza e } \\
\text { Escritorio } \\
\end{array}$ & 118,00 & 124,78 & 97,15 & 44,97 & 32,00 & 276,89 & 117,98 & 110,00 & 149,00 & 560,00 & 77,00 & 34,50 \\
\hline Pró Labore & $1.868,00$ & $1.868,00$ & $1.868,00$ & $1.868,00$ & $1.868,00$ & $1.868,00$ & $1.868,00$ & $1.868,00$ & $1.868,00$ & $1.868,00$ & $1.868,00$ & $1.868,00$ \\
\hline TOTAL & $3.820,96$ & $4.193,85$ & $4.179,12$ & $4.180,61$ & $4.747,78$ & $4.145,79$ & $4.044,06$ & $4.158,10$ & $3.876,97$ & $4.477,96$ & $4.569,74$ & $3.957,97$ \\
\hline
\end{tabular}

A Tabela 5 demonstra a relação de despesas incorridas nos meses de janeiro de 2011 a dezembro de 2011 na empresa Alfa, na qual observa-se que as maiores despesas estão relacionadas aos valores pagos com os honorários contábeis e com a retirada do pró labore.

Os valores com relação ao pró labore lançados na tabela 5, estão apropriados às retiradas dos dois sócios da empresa Alfa, em seguida estão demonstrados também as demais despesas como água, energia, telefone, combustíveis e materiais de limpeza da parte do escritório.

\subsection{Serviços escolhidos para a análise de custos e formação do preço de venda}

Com base nas observações realizadas na empresa Alfa, foram escolhidos os serviços que proporcionam maior rendimento financeiro para a empresa e aplicados a esta análise para simulação do preço de venda destes serviços.

$\mathrm{Na}$ elaboração dos orçamentos, o produto é deixado pelo cliente na loja onde é recepcionado pela pessoa responsável do setor de atendimento. Esse processo é realizado afim de que possam ser passadas as informações necessárias para o atendente, por exemplo, a reclamação do produto, dados do consumidor e todas as informações que possam ser úteis na elaboração do orçamento de determinado produto.

Em seguida o técnico responsável pelo setor, seja ele do setor de eletrodomésticos ou climatização, é orientado sobre a reclamação do produto e este realiza todos os testes no aparelho para depois passar o orçamento para o cliente.

O primeiro serviço escolhido foi revisão/limpeza de condicionadores de ar split, que para desenvolvimento do estudo, este serviço será denominado de serviço "A". No caso deste 
Utilização da metodologia de custeio ABC na formação do preço de venda de serviços na empresa "Alfa" em Tangará da Serra - MT

Edenize de Almeida Gomes

Marcelo Evandro Alves

tipo de serviço o consumidor não leva o produto até a loja, já que este tem a necessidade da desmontagem do aparelho e esta desmontagem só é feita com o auxilio de um técnico especializado, portanto o cliente não conseguiria realizar a desmontagem.

O segundo serviço escolhido foi carga de gás em refrigeradores, que para desenvolvimento do estudo será denominado de serviço "B". Este tipo de serviço é muito solicitado na empresa Alfa, haja vista que a maioria das residências possuem refrigeradores e é um tipo de produto essencial na conservação de alimentos perecíveis.

O terceiro serviço escolhido foi revisão/óleo em lavadoras de roupas eletrônicas, é também um dos serviços mais procurados na empresa Alfa, e para desenvolvimento do estudo será denominado de serviço "C". O processo de revisar uma lavadora eletrônica é extremamente demorado, pois é feito a desmontagem e troca de peças danificadas pelo uso e posteriormente feito a troca do óleo da parte mecânica do produto.

Tabela 6 - Preços Praticados na Empresa Alfa, Serviços Escolhidos.

\begin{tabular}{l|c|c|c}
\hline SERVIÇOS & "A" & "B” & “C” \\
\hline Receita dos Serviços Prestados & 120,00 & 187,00 & 320,00 \\
\hline FGTS 8\% & 9,60 & 14,96 & 25,60 \\
\hline Simples 6\% & 7,20 & 11,22 & 19,20 \\
\hline Comissão dos técnicos & 70,00 & 50,00 & 60,00 \\
\hline LUCRO LÍQUIDO & 33,20 & 110,82 & 215,20 \\
\hline
\end{tabular}

Fonte: Dados da pesquisa.

A tabela 6 demonstra os serviços escolhidos para análise do preço de venda e seus respectivos preços praticados. O lucro ocorre para os três tipos de serviço, a diferença é somente quanto aos valores que correspondem ao lucro.

O serviço "C" é o que proporcionou maior rendimento para a empresa Alfa, no qual o preço praticado corresponde ao valor de $\mathrm{R} \$ 320,00$ reais e o lucro obtido ficou no valor de $\mathrm{R} \$$ 215,20. Além de obter o maior rendimento com relação a valores, foi constatado que o serviço "C" retém a maior parte dos rendimentos, pois possui o maior número de solicitações na empresa Alfa.

\subsection{Formação do preço de venda com mark-up}

Para a formação do preço de venda da empresa Alfa, será utilizada uma taxa sobre os custos dos serviços para que, posteriormente, se chegar ao preço de venda e, essa taxa é denominada de mark-up. 
Utilização da metodologia de custeio ABC na formação do preço de venda de serviços na empresa "Alfa" em Tangará da Serra - MT

Edenize de Almeida Gomes

Marcelo Evandro Alves

Foi feito uma simulação do preço que a empresa poderia adotar nos serviços realizados, e uma comparação entre o preço simulado e o já praticado pela empresa Alfa, existem duas formas de se calcular o preço de venda com o mark-up, o divisor e o multiplicador, ambos já foram mencionados no item 3.1.

Nas tabelas abaixo foram apresentados os preços de venda dos serviços "A", "B" e "C", com o auxilio do mark-up, desta forma os serviços escolhidos serão comparados ao preço praticados na empresa Alfa.

Na primeira etapa, foi feito o cálculo do índice mark-up com base nos percentuais dos impostos e com a margem de lucro desejada, que no caso da análise foi de $20 \%$. Em seguida, utilizando o valor gerado pelo índice mark-up, obteve-se os valores dos preços de venda dos serviços “A", "B" e "C". A tabela 7 demonstra os percentuais usados para o cálculo do índice mark-up, onde foi feita a soma dos impostos que ficou no valor de $14 \%$ e a margem de lucro desejada, que para efeitos desta análise foi no valor de $20 \%$.

Tabela 7 - Percentuais usados para cálculo do mark-up

\begin{tabular}{l|l}
\hline Preço de Vendas & $100 \%$ \\
\hline Impostos & \\
\hline FGTS & $8 \%$ \\
\hline Simples & $6 \%$ \\
\hline MLD & $20 \%$ \\
\hline Impostos (+) MLLD $=$ & $34 \%$ \\
\hline
\end{tabular}

Fonte: Dados da pesquisa

Cálculo do Mark-up

$(1-0,34)=0,66$

\section{Cálculo do preço de venda serviço "A"}

$\mathrm{PV}=\mathrm{Custo} / \mathrm{markup}$

$\mathrm{PV}=\mathrm{R} \$ 86,80 / 0,66$

$\mathrm{PV}=\mathrm{R} \$ 131,51$

\section{Cálculo do preço de venda serviço "B"}

$\mathrm{PV}=\mathrm{Custo} / \mathrm{markup}$

$\mathrm{PV}=\mathrm{R} \$ 76,18 / 0,66$

$\mathrm{PV}=\mathrm{R} \$ 115,42$ 
Utilização da metodologia de custeio ABC na formação do preço de venda de serviços na empresa "Alfa" em Tangará da Serra - MT

Edenize de Almeida Gomes

Marcelo Evandro Alves

Cálculo do preço de venda serviço " $C$ "

$\mathrm{PV}=\mathrm{Custo} / \mathrm{markup}$

$\mathrm{PV}=\mathrm{R} \$ 104,80 / 0,66$

$\mathrm{PV}=\mathrm{R} \$ 158,78$

Tabela 8 - Cálculo e Análise entre o Preço Simulado e o Praticado na empresa Alfa/ Serviço “A” - em R\$

\begin{tabular}{l|l|l}
\hline ITENS & SIMULADO & PRATICADO \\
\hline $\mathbf{1}$-Preço de Venda Serviços Prestados & $\mathbf{R} \$ \mathbf{1 3 1 , 5 1}$ & $\mathbf{R \$ 1 2 0 , 0 0}$ \\
\hline (-) Impostos 14\% & $\mathrm{R} \$ 18,41$ & $\mathrm{R} \$ 16,80$ \\
\hline (=) Preço de venda & $\mathbf{R} \$ \mathbf{1 1 3 , 1 0}$ & $\mathbf{R} \mathbf{1 0 3 , 2 0}$ \\
\hline (-) MLD 20\% & $\mathrm{R} \$ 26,30$ & $\mathrm{R} \$ 24,00$ \\
\hline Preço de venda liquido & $\mathbf{R} \mathbf{8 6 , 8 0}$ & $\mathbf{R} \mathbf{7 9 , 2 0}$ \\
\hline (-) Despesas Gerais 10\% & $\mathrm{R} \$(13,15)$ & $\mathrm{R} \$ 12,00$ \\
\hline (=)Lucro & & $\mathbf{R \$ ~ 6 7 , 2 0}$ \\
\hline
\end{tabular}

Fonte: Dados da pesquisa.

A tabela 8 apresenta o preço simulado do serviço "A" em comparação com o praticado na empresa Alfa, no qual o preço atual praticado pela empresa é no valor de $\mathrm{R} \$ 120,00$ e o preço simulado foi de $\mathrm{R} \$ 131,51$ reais.

O lucro obtido na simulação pelo serviço "A" ficou no valor de $R \$ 73,65$, enquanto que no preço praticado este valor era de apenas $R \$ 67,20$. Houve assim, uma diferença de $R \$$ 6,45 de lucro em relação ao preço praticado e o simulado na análise. No caso do serviço "A", a empresa obteve maior rendimento, se comparados com os valores da prestação de serviços já praticados na empresa.

O mesmo procedimento foi aplicado na tabela 9, que com a simulação do preço de venda do serviço "B” obteve-se os seguintes resultados.

Tabela 9 - Cálculo e análise entre o preço simulado e o praticado na empresa Alfa/ Serviço “B” - em R\$

\begin{tabular}{l|l|l}
\hline ITENS & SIMULADO & PRATICADO \\
\hline $\mathbf{1}$-Preço de Venda Serviços Prestados & $\mathbf{R} \mathbf{1 1 5 , 4 2}$ & $\mathbf{R} \mathbf{1 8 7 , 0 0}$ \\
\hline (-) Impostos 14\% & $\mathrm{R} \$ 16,15$ & $\mathrm{R} \$ 26,18$ \\
\hline (=) Preço de venda & $\mathbf{R} \mathbf{9 9 , 2 7}$ & $\mathbf{R} \$ \mathbf{1 6 0 , 8 2}$ \\
\hline (-) MLLD 20\% & $\mathrm{R} \$ 23,08$ & $\mathrm{R} \$ 37,40$ \\
\hline
\end{tabular}


Utilização da metodologia de custeio ABC na formação do preço de venda de serviços na empresa "Alfa" em Tangará da Serra - MT

Edenize de Almeida Gomes

Marcelo Evandro Alves

\begin{tabular}{l|l|l}
\hline Preço de venda liquido & $\mathbf{R} \$ \mathbf{7 6 , 1 9}$ & $\mathbf{R} \mathbf{1 2 3 , 4 2}$ \\
\hline (-) Despesas Gerais 10\% & $\mathrm{R} \$ 11,54$ & $\mathrm{R} \$ 18,70$ \\
\hline (=)Lucro & $\mathbf{R} \$ \mathbf{6 4 , 6 5}$ & $\mathbf{R} \mathbf{1 0 4 , 7 2}$ \\
\hline
\end{tabular}

Fonte: Dados da pesquisa.

Na tabela 9 estão relacionados os valores referente a simulação do preço de venda do serviço "B" em comparação com o preço já praticado na empresa Alfa. O preço para simulação do serviço “B” ficou estipulado em $\mathrm{R} \$ 115,42$, onde preço praticado é no valor de $\mathrm{R} \$ 187,00$.

Com o preço praticado pela empresa Alfa o lucro obtido com o serviço "B" ficou no valor de R \$104,72, já com na simulação do preço de venda, este serviço proporciona um lucro no valor de $\mathrm{R} \$ 64,65$ reais.

Com isso percebe-se uma diferença de $\mathrm{R} \$ 40,07$ reais de lucro para empresa Alfa, em relação ao preço. No caso do serviço "B", o lucro obtido deste serviço foi maior com os valores ja praticados. Cerca de $10 \%$ são das despesas gerais e estão relacionados ao uso de produtos para manutenção do serviço "B".

Da mesma forma o produto "C" também apresentou os valores referentes aos preços praticados e os valores obtidos no estudo do preço simulado na empresa Alfa. Estes dados estão demonstrados na tabela 10.

Tabela 10 - Cálculo e análise entre o preço simulado e o praticado na empresa Alfa/ Serviço “C” - em R\$

\begin{tabular}{l|l|l}
\hline ITENS & SIMULADO & PRATICADO \\
\hline 1 -Preço de Venda Serviços Prestados & R\$ 158,78 & $\mathbf{R} \$ \mathbf{3 2 0 , 0 0}$ \\
\hline (-) Impostos 14\% & $\mathrm{R} \$ 22,22$ & $\mathrm{R} \$ 44,80$ \\
\hline (=) Preço de venda & $\mathbf{R} \$ \mathbf{1 3 6 , 5 6}$ & $\mathbf{R} \mathbf{2 7 5 , 2 0}$ \\
\hline ( -) MLLD 20\% & $\mathrm{R} \$ 31,75$ & $\mathrm{R} \$ 64,00$ \\
\hline Preço de venda liquido & $\mathbf{R} \mathbf{1 0 4 , 8 1}$ & $\mathbf{R} \mathbf{2 1 1 , 2 0}$ \\
\hline (-) Despesas Gerais 10\% & $\mathrm{R} \$ 15,87$ & $\mathrm{R} \$ 32,00$ \\
\hline (=)Lucro & & $\mathbf{R} \mathbf{1 7 9 , 2 0}$ \\
\hline
\end{tabular}

Fonte: Dados da pesquisa.

A tabela 10 apresenta que no preço de venda simulado do serviço "C" o lucro obtido foi de $\mathrm{R} \$ 88,94$, uma diferença de $\mathrm{R} \$ 90,26$ em comparação com o lucro obtido no preço de 
Utilização da metodologia de custeio ABC na formação do preço de venda de serviços na empresa "Alfa" em Tangará da Serra - MT

Edenize de Almeida Gomes

Marcelo Evandro Alves

venda praticado pela empresa Alfa que era de $\mathrm{R} \$ 179,20$.

O preço de venda praticado pela empresa deste serviço é no valor de $\mathrm{R} \$ 320,00$ e para simulação do estudo foi estipulado o valor de R\$ 158,78. No serviço "C" o lucro foi maior com os valores que já são praticados, assim como ocorreu no serviço "C".

\section{CONSIDERAÇÕES FINAIS}

Com base nos dados levantados, foram evidenciados os custos diretos, custos indiretos e despesas que os departamentos proporcionam para a empresa Alfa. Conclui-se que a maior parte dos custos diretos estão relacionados ao valor gasto com a folha de pagamento, quanto aos custos indiretos os valores pagos com água, energia e telefone e por fim as despesas que são consumidas pelos valores pagos com honorários contábeis e as retiradas de pró labore.

Em resposta a hipótese 1, o método de custeio $\mathrm{ABC}$ não é aplicável nas empresas prestadoras de serviço, pois este tipo de sistema requer que os dados estejam em ordem, requer que exista um controle detalhado de todos os custos e despesas.

Em resposta a hipótese 2, o sistema de custeio $\mathrm{ABC}$ não traz benefícios para as empresas prestadoras de serviço, pois este sistema de custeio é melhor aplicável nas indústrias, onde os dados possuem maior riqueza de detalhes.

Quanto aos objetivos específicos, estes foram alcançados, pois através deste estudo foram demonstrados os valores dos custos diretos, indiretos e despesas. Foram também evidenciados os valores dos custos dos departamentos, em resposta ao problema sugerido pela pesquisa.

Pelo fato da empresa Alfa não utilizar nenhum tipo de custeio sugere-se que seja utilizado o sistema de custeio $\mathrm{ABC}$, pois mais importante que formar o preço de venda dos serviços é saber quais são os custos, gastos, despesas que ocorrem na entidade e se estas proporcionam o lucro desejado.

\section{REFERÊNCIAS BIBLIOGRÁFICAS}

BENARDI, Luis Antonio. Politica e formação de preços: uma abordagem competitiva, sistemica e integrada.São Paulo: ed.Atlas - 1998.

BEULKE, Rolando;BERTÓ, Dalvio José. Estrutura e análise de custos. São Paulo Saraiva, 2001.

BORNIA,Antonio Cezar. Análise Gerencial de Custos. Porto Alegre - Bookman, 2002.

BRIMSON, James A. Contabilidade por atividades. São Paulo - Atlas S/A, 1996. 
BRUNI, Adriano Leal. Gestão de custos e formação de preços. São Paulo - Atlas, 2002.

BRUNI, Adriano Leal.;FAMÁ, Rubens.Gestão de custos e formação de preços: com aplicações na calculadora HP 12C e excel. São Paulo - Atlas, 2002.

COGAN, Samuel. Activity - Based Costing (ABC) - A poderosa estratégia empresarial. São Paulo - Ed. Pioneira, 2000.

CREPALDI, Silvio Aparecido.Curso básico de contabilidade de custos. São Paulo: Atlas S/A, - 2004.

DUTRA, Rene Gomes.Custos:uma abordagem na prática. São Paulo - Atlas, 2003.

FITZSIMMONS,J.A.;FITZSIMMONS,M.J.Administração de Serviços: operaçãoes, estrátegias e tecnologia.Porto Alegre - Bookman, 2000.

GARRISON, R.H .Contabilidade gerencial. Rio de Janeiro: Ltc, - 2001.

KAPLAN, R.S.; COOPER, R. Custo e desempenho - administre seus custos para ser mais competitivo.São Paulo - Editora Futura, 1998.

LEONE, George S.G. Contabilidade de custos.São Paulo - Atlas, 1991.

LOBRIGETTI, Luis Alberto Fernando. Custos na prestação de serviços. Disponível $\mathrm{em}:<$ http://www.slidesshare.net/padme/contabil-custos-na-prestação-de-serviços. $>$ Acesso em : 13 de Setembro de 2011.

MARTINS, Eliseu. Contabilidade de custos. São Paulo: Atlas S.A, - 2003.

MAUAD, L.G A.; PAMPLONA,E.Ó. Abc/Abm e Bsc: Como essas ferramentas podem se tornar valiosas aliadas dos tomadores de decisão das empresas. Congresso Internacional de Custos, VIII ed., 2003. Disponivel em: $<$ http://www.tecsi.fea.usp.br/mauad/artigos/pdf/abc_serviços.pdf $>$ Acesso em: 02 de Setembro de 2011.

MEDEIROS, Luiz Edgar. Contabilidade de custos: Um Enfoque Prático. Porto Alegre: ed.Ortiz - 1994.

MEGLIORINI, Evandir. Custos: Analise e gestão . Ed.São Paulo: Pearson Prentice Hall, 2007.

OLIVERA JR,Renato Gomes de.Utilização do custeio por absorção na formação do preço de venda de serviços com base nos custos da empresa Alfa auto mecânica. Tangará da Serra - Unemat, 2010.

PADOVEZE, Clovis Luiz.Curso básico gerencial de custos. São Paulo - Thomnson, 2003. 
Utilização da metodologia de custeio ABC na formação do preço de venda de serviços na empresa "Alfa" em Tangará da Serra - MT

Edenize de Almeida Gomes Marcelo Evandro Alves

RIBEIRO, Magno Alves; TORRES, Ariel Lopes; ROCHA, Margarida Alves. Manual para elaboração e apresentação de monografias: com noções introdutórias de metodologia. Tangará da Serra - Unemat, 2006.

RICCIO, Junior. Sistemas de Custos baseado em atividades nas empresas de serviços. Revista de Contabilidade do CRC - SP, Nov. 1998.Disponível em: $<$ http://cenbio.iee.usp.br/download/projetos/8_sist-cust.pdf $>$ Acesso em: 12 de Setembro de 2011.

SANTOS, Joel J. Fundamentos de Custos para formação do preço e do Lucro.

São Paulo - Atlas S.A., 2005.

VERGARA, Sylvia Constant.Projetos de Pesquisa em administração. São Paulo - Atlas, 2000. 